\title{
Safety Precautions to be Observed with Cooled Premixed Gases
}

\author{
A. BRACKEN,* B.SC., PH.D., F.R.I.C.; G. B. BROUGHTON, $†$ B.SC.ENG. \\ D. W. HILL, $\ddagger$ M.SC., PH.D., F.INST.P., F.I.E.E.
}

Brit. med. F., 1968, 3, 715-716

\begin{abstract}
Cummary: The gas delivered from a cylinder of Entonox (50\% nitrous oxide and $50 \%$ oxygen) may not contain adequate quantities of oxygen if the cylinder has been cooled and then allowed to warm up in a vertical position.
\end{abstract}

The composition of gas delivered from cylinders cooled to not lower than $-40^{\circ}$ C. remains unaltered if the cylinders are rewarmed for 24 hours in a horizontal position at a temperature of not less than $5^{\circ} \mathrm{C}$.

Cylinders of Entonox delivered in cold weather should be stored in a horizontal position at $5^{\circ} \mathrm{C}$. or more for at least 24 hours before use.

\section{Introduction}

A mixture of $50 / 50$ by volume nitrous oxide and oxygen supplied in cylinders under the trade mark Entonox is now being used in obstetrical practice and its application to the relief of postoperative pain is being investigated. A number of workers have drawn attention to the fact that partial liquefaction of the cylinder contents is likely to occur when cylinders of Entonox are cooled below about $-7^{\circ} \mathrm{C}$. This temperature is best termed as the "condensation" or "liquefaction" temperature for this particular mixture. Since the system under consideration consists of two components, a single critical point under the usually accepted definition for a single component system does not exist. As a result of this liquefaction the mixture drawn initially from a full cylinder contains more than $50 \%$ oxygen, but as the cylinder is emptied the oxygen concentration falls until in severe cases the final portion of the cylinder contents may consist of a hypoxic mixture (Tunstall, 1963 ; Cole, 1964 ; Gale et al., 1964 ; Crawford et al., 1967). In order to prevent this situation from arising in practice, provision must be made for warming a cylinder which has been cooled to allow any condensed phase to evaporate. The present study was undertaken to determine the most convenient precautions which could be taken to ensure that a patient will always inspire a mixture which is virtually of a $50 / 50$ composition.

\section{Materials and Method}

A total of 112 cylinders containing 50/50 nitrous oxide and oxygen were investigated in this study. Of these, six were cylinders containing 500 litres of mixture, 100 contained 2,000 litres, and six contained 5,000 litres. Most cylinders were filled to approximately $2,000 \mathrm{lb}$./sq. in. (139 kg./sq. cm.) on the gauge. Some cylinders were supplied filled with the Entonox mixture by the British Oxygen Company; others were filled in the laboratory by means of a Siebe Gorman rocking cylinder compressor. The necessary amount of nitrous oxide was pumped into an evacuated cylinder, the weight checked with a balance, and then the oxygen admitted to the required

\footnotetext{
* Scientific Centre, British Oxygen Company Limited, London S.W.19. t Research Department of Anaesthetics, Royal College of Surgeons of England, London W.C.2.

\pm Research Department of Anaesthetics, Royal College of Surgeons of england, London W.C.2, and Institutes of Basic Medical Sciences and Urology, University of London. London W.C.1.
}

pressure. The filled cylinder was inverted several times and laid in a horizontal position for at least 24 hours in order to mix the contents.

\section{Storage, Cooling, and Rewarming}

Two methods of cooling were available. Where the cylinders were of the 5,000-litre type, or when a number of 2,000-litre cylinders of Entonox were required to be cooled at one time, a "cold box" was employed. This insulated chamber of 600-700 cu. ft. (17-19.8 cu. m.) capacity could be cooled to $-45^{\circ}$ C. by means of an overhead liquid nitrogen spray. Temperatures were measured by means of two thermocouples, one of which recorded the "box" temperature and the other was attached to one of the cylinders being cooled.

In most cases the cylinders could be cooled down to the selected temperature in one hour. The cylinders were generally held at the required temperature for a period of one hour before being removed from the box, but in certain tests this period was extended.

The second method involved cooling the cylinder being investigated to $-20^{\circ} \mathrm{C}$. in a bath of anti-freeze fluid. The bath contained the cooling coil of a compressor-type refrigerator and the cylinder was placed inside the helical coil. The fluid was continuously agitated by pumping through it a stream of dry air, and the uniformity of the bath temperature was checked by means of a thermocouple placed at the top, middle, and bottom of the bath. Additionally, one cylinder was fitted with three internal thermocouples so that the temperature distribution of the contents could be determined, and one further cylinder contained a dip tube which reached down to the bottom of the cylinder in order that any condensed gas could be sampled. Cylinders were cooled in a vertical position, except in a few specified cases.

After storage at the desired temperature the cylinders were removed to a room which had a constant known temperature in the range 0 to $10^{\circ} \mathrm{C}$. Here they were allowed to warm for a predetermined time in either a horizontal or a vertical position.

\section{Gas Analysis}

The oxygen content of the cylinder mixtures was measured by means of a null-balance paramagnetic oxygen analyser type DCL 101 by Servomex Ltd. The accuracy of this type of analyser has been compared by Nunn et al. (1964) with that of the Lloyd-Haldane chemical gas analyser (Lloyd, 1958) and found to agree well.

\section{Emptying the Cylinder}

As cylinders were cooled the minimum possible volume of gas was removed and fed into the oxygen analyser in order to confirm that composition changes could be expected when the temperature was below $-7^{\circ} \mathrm{C}$. The removal of these small samples did not affect the composition of the mixture. After cylinders had been subjected to various methods of rewarming they were run down to zero pressure at a steady flow rate of 10,20 , or 30 litres pér minute, measured on a calibrated rotameter, and the composition of the issuing gas checked at 
intervals. The flow rate of 30 litres per minute was chosen as being the maximum average flow rate which would be encountered in obstetric practice.

\section{Composition of Emergent Mixture}

A total rewarming period of not less than 24 hours at a temperature not lower than $-5^{\circ} \mathrm{C}$. with the cylinder stored in a horizontal position always restored the mixture composition so that the oxygen content lay within plus or minus $1 \% \mathrm{v} / \mathrm{v}$ of the original Entonox mixture tolerance of 48 to $52 \% \mathrm{v} / \mathrm{v}$.

With the cylinder stored in the vertical position and with no agitation, it took several weeks for the mixtures to reconstitute. For this reason ventical storage of Entonox cylinders during cold frosty weather should be prohibited. The effect of reducing cylinder temperatures to $-40^{\circ} \mathrm{C}$. was investigated by cooling eight cylinders to $-40^{\circ} \mathrm{C}$. for one hour. It was found that their oxygen contents were within plus or minus $2 \% \mathrm{v} / \mathrm{v}$ of the original composition when they were rewarmed in a horizontal position for 24 hours at $5^{\circ} \mathrm{C}$.

A cylinder that had been cooled to $-20^{\circ} \mathrm{C}$. attained a surface temperature of about $5^{\circ} \mathrm{C}$. within half an hour of removal from the coolant bath when warmed at room temperature in a vertical position (and it did not then feel particularly cold to the touch). However, analysis revealed that the mixture obtained first from the cylinder was now rich in oxygen compared with the original $50 \%$ value while the final gas was low. Whether or not hypoxic mixtures were obtained from unagitated cylinders stored in a vertical position depended on the length of time between removal from the coolant bath and the onset of venting. Experiments with the cylinder fitted with a dip tube confirmed that the effect arises from a progressive change in the composition of the condensed phase. The proportion of nitrous oxide steadily rises if venting is started after an insufficient period of rewarming. If venting was started after only a matter of minutes of removal from the coolant bath the composition of the last few litres of gas issuing from the cylinder was, in fact, $100 \%$ nitrous oxide. If 24 hours were allowed to elapse before venting was started, then the composition of the last few litres was about $29 \%$ oxygen.

\section{Discussion}

Temperatures of -7 to $-8^{\circ} \mathrm{C}$. occur on a number of occasions each year in the United Kingdom, while temperatures of $-20^{\circ} \mathrm{C}$. are common in Germany and $-40^{\circ} \mathrm{C}$. is often recorded in Norway and Canada. For this reason, care must be taken to ensure that cylinders of premixed gas which have been cooled sufficiently for separation to occur are not used until they have been adequately warmed and mixed. The British Oxygen Company cylinder label states that cylinders of Entonox must not be stored in the open, and that if an Entonox cylinder has been cooled below $0^{\circ} \mathrm{C}$. or has ice on it, then before use the cylinder should be warmed for five minutes in warm water at a temperature not exceeding $35^{\circ} \mathrm{C}$. Finally, the cylinder must be inverted three times. The study of Crawford et al. (1967) confirms that these precautions are adequate, though the absence of ice on cylinders is not a guarantee of safety. Cylinders which have been exposed to low temperatures during delivery may feel warm to the touch on arrival ; these could escape the regulation remixing procedure and yet still contain potentially dangerous mixtures. Moreover, the routine inversion of cylinders may prove to be inconvenient and would be virtually impossible to carry out in the case of 5,000 -litre cylinders.

Our discovery that horizontal storage for 24 hours at $5^{\circ} \mathrm{C}$. leads to reconstitution (to within $1 \% \mathrm{v} / \mathrm{v}$ of the original composition) of mixtures separated by cooling from 0 to $-20^{\circ} \mathrm{C}$. (within $2 \% \mathrm{v} / \mathrm{v}$ for mixtures separated by cooling from -20 to $-40^{\circ} \mathrm{C}$.) overcomes this difficulty. For this reason we propose that all cylinders of Entonox mixture delivered in cold weather should be stored horizontally in a room the temperature of which does not fall below $5^{\circ} \mathrm{C}$. for 24 hours before being issued as fit for use. The temperature of $5^{\circ} \mathrm{C}$. is selected in order to provide a margin of safety.

The markedly more rapid redistribution of the cylinder contents in the horizontal position when compared with the vertical arises from the larger area of interface between the liquid and gaseous phase and the smaller distance between the surface and the cylinder wall. This facilitates a more rapid evaporation and diffusion.

Hypoxic mixtures can be obtained only from cylinders which initially contained a condensed gas phase. When a cylinder containing some condensed phase is full the condensate is not necessarily of a hypoxic composition. It can become so as the cylinder is emptied, depending on the rate of withdrawal of gas and the period of rewarming. A 2,000-litre cylinder may, under the worst conditions, have an oxygen content of less than $21 \%$ in its last 500 litres, but a more typical value is likely to be 150 litres.

Two of us (G.B.B. and D.W.H.) are indebted to the Science Research Council for support, and to the British Oxygen Company, who provided cylinders of Entonox and also cylinders fitted with thermocouples and dip tubes.

\section{REFERENCES}

Cole, P. V. (1964). Anaesthesia, 19, 3.

Crawford, J. S., Ellis, D. B., Hill, D. W., and Payne, J. P. (1967). Brit. med. $¥ . .2,138$.

Gale, C. W., Tunstall, M. E., and Wilton-Davies, C. C. (1964). Brit. med. $3 ., 1,732$.

Lloyd, B. (1958). 3. Physiol. (Lond.), 143, 5P.

Nunn, J. F., Bergman, N. A., Coleman, A. J., and Casselle, D. C. (1964). Brit. F. Anaesth., 36, 666.

Tunstall, M. E. (1963). Brit. med. 7., 2, 915. 